\title{
Complement Component C3 and Complement Factor B Promote Growth of Cutaneous Squamous Cell Carcinoma
}

Pilvi Riihilä, ${ }^{* \dagger}$ Liisa Nissinen, ${ }^{* \dagger}$ Mehdi Farshchian, ${ }^{* \dagger}$ Markku Kallajoki, ${ }^{\ddagger}$ Atte Kivisaari, ${ }^{\star \dagger}$ Seppo Meri, ${ }^{\S}$ Reidar Grénman, ${ }^{\oplus}$ Sirkku Peltonen, ${ }^{*}$ Juha Peltonen, Taina Pihlajaniemi, ${ }^{* *}$ Ritva Heljasvaara, ${ }^{* * \dagger \dagger}$ and Veli-Matti Kähäri*†

From the Department of Dermatology, * University of Turku and Turku University Hospital, Turku, Finland; the MediCity Research Laboratory ${ }^{\dagger}$ and Department of Cell Biology and Anatomy, "University of Turku, Turku, Finland; the Departments of Pathology $y^{\ddagger}$ and Otorhinolaryngology-Head and Neck Surgery, ${ }^{\Phi}$ Turku University Hospital, Turku, Finland; the Haartman Institute, ${ }^{\S}$ University of Helsinki, Helsinki, Finland; the Oulu Center for Cell-Matrix Research,** Biocenter Oulu and the Faculty of Biochemistry and Molecular Medicine, University of Oulu, Oulu, Finland; and the Centre for Cancer Biomarkers CCBIO ${ }^{\dagger \dagger}$ Department of Biomedicine, University of Bergen, Bergen, Norway

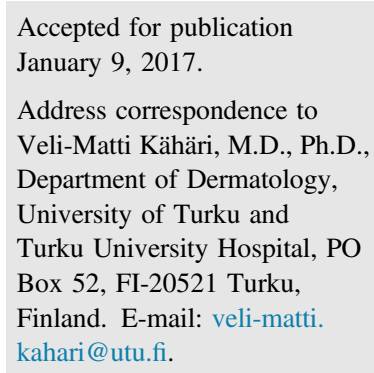

\begin{abstract}
Cutaneous squamous cell carcinoma ( $\mathrm{CSCC}$ ) is one of the most common metastatic skin cancers with increasing incidence. We examined the roles of complement component $\mathrm{C} 3$ and complement factor $\mathrm{B}$ (CFB) in the growth of CSCC. Analysis of CSCC cell lines $(n=8)$ and normal human epidermal keratinocytes $(n=11)$ with real-time quantitative PCR and Western blotting revealed up-regulation of C3 and CFB expression in CSCC cells. Immunohistochemical staining revealed stronger tumor cell-specific labeling for C3 and CFB in invasive CSCCs $(n=71)$ and recessive dystrophic epidermolysis bullosaassociated $\operatorname{cSCCs}(n=11)$ than in $\operatorname{CSCC}$ in situ $(n=69)$, actinic keratoses $(n=63)$, and normal skin $(n=5)$. Significant up-regulation of C3 and CFB mRNA expression was noted in chemically induced mouse CSCCs, compared to benign papillomas. Knockdown of C3 and CFB expression inhibited migration and proliferation of $\mathrm{CSCC}$ cells and resulted in potent inhibition of extracellular signal-regulated kinase $1 / 2$ activation. Knockdown of C3 and CFB markedly inhibited growth of human CSCC xenograft tumors in vivo. These results provide evidence for the roles of C3 and CFB in the development of CSCC and identify them as biomarkers and potential therapeutic targets in this metastatic skin cancer. (Am J Pathol 2017, 187: 1186-1197; http://dx.doi.org/10.1016/j.ajpath.2017.01.006)
\end{abstract}

Cutaneous squamous cell carcinoma (cSCC) is a keratinocyte-derived skin cancer, which is responsible for the majority of nonmelanoma skin cancer-related mortality. ${ }^{1}$ The incidence of cSCC and its precursors [ie, actinic keratosis (AK) and cSCC in situ (cSCCIS)] is increasing worldwide. $^{2}$ Solar UV radiation is the major risk factor for cSCC, which typically arises in the sun-exposed areas of skin. Other important risk factors for cSCC include chronic cutaneous ulceration and immunosuppression. ${ }^{3}$ In addition, chronic inflammation plays an important role in cSCC progression. ${ }^{4}$

The complement system is a part of both the innate and acquired immune systems. It can be activated via three distinct pathways (ie, the classic, lectin, and alternative pathways). ${ }^{5} \mathrm{C} 3$ is a central component in the complement system and connects innate and acquired immunity. All three pathways converge to activation of $\mathrm{C} 3$ by cleavage of $\mathrm{C} 3$ to fragments $\mathrm{C} 3 \mathrm{a}$ and $\mathrm{C} 3 \mathrm{~b}$. This results in activation of the terminal pathway of complement and finally to formation of membrane attack complex, lysis of the target

\footnotetext{
Supported by Finnish Cancer Research Foundation grant, Sigrid Juselius Foundation grant, Jane and Aatos Erkko Foundation grant, Turku University Hospital grant (project 13336), the Health Science Council of the Academy of Finland grant 251314 (Center of Excellence 2012-2017), and Finnish Dermatological Association grant (P.R.), Finnish Dermatopathology Society grant (P.R.), Turku University Foundation grant (P.R.), Southwestern Cancer Society of Finland grant (P.R.), The Finnish Medical Foundation and Finnish Cultural Foundation grant (P.R.), Southwestern Finland Regional Fund grant (P.R.).

Disclosures: None declared.
} 
cell, onset of inflammation, and macrophage or B-cell stimulation. ${ }^{6,7} \mathrm{C} 3 \mathrm{a}$ is an anaphylatoxin, and $\mathrm{C} 3 \mathrm{~b}$ binds covalently to the surface of foreign and host cells. On host cell surface, the $\mathrm{C} 3 \mathrm{~b}$ fragment is inactivated by different soluble and membrane-bound inhibitors [ie, complement factors $\mathrm{H}$ and I, complement receptor 1 (CD35), membrane cofactor protein (CD46), and decay accelerating factor $(\mathrm{CD} 55)]^{5,8}$

The classic pathway of the complement system is activated by antibody/antigen complexes, and the lectin pathway is activated by specific carbohydrates on microbial surfaces. In the alternative pathway, constant spontaneous breakdown of $\mathrm{C} 3$ takes place at low level in plasma, resulting in formation of complex $\mathrm{C} 3 \mathrm{~b}\left(\mathrm{H}_{2} \mathrm{O}\right)$ (alias iC3). Complement factor $\mathrm{B}(\mathrm{CFB})$ is an important soluble component in the alternative pathway. ${ }^{8} \mathrm{CFB}$ binds to $\mathrm{C} 3 \mathrm{~b}\left(\mathrm{H}_{2} \mathrm{O}\right)$ and is cleaved by complement factor $\mathrm{D}$, a serine proteinase, to fragments $\mathrm{Ba}$ and $\mathrm{Bb}$. The activated component $\mathrm{Bb}$ is a serine proteinase, which remains attached to $\mathrm{C} 3 \mathrm{~b}$ and forms the alternative pathway convertase, $\mathrm{C} 3 \mathrm{bBb}$. This convertase is a key enzyme in the activation of the alternative pathway, as it cleaves more $\mathrm{C} 3$ to $\mathrm{C} 3 \mathrm{~b}$, generating an amplification loop for the activation of the alternative pathway.

Previous studies have shown that normal human epidermal keratinocytes (NHEKs) produce $\mathrm{C} 3$ and $\mathrm{CFB}^{9}$ and that their production is regulated by inflammatory cytokines. ${ }^{10}$ Inhibitors of the complement system are also produced by epidermal keratinocytes. ${ }^{11,12}$ We have previously reported that the expression of two important inhibitors of the alternative pathway, complement factors $\mathrm{H}$ and $\mathrm{I}$, is specifically up-regulated in tumor cells in cSCCs. ${ }^{13,14}$ In addition, expression profiling of cSCC cell lines has revealed elevated expression of $\mathrm{C} 3$ and $\mathrm{CFB}$ mRNAs, as compared to NHEKs. ${ }^{13,14}$

Herein, we have examined the roles of $\mathrm{C} 3$ and $\mathrm{CFB}$ in the development of cSCC. The results show specific up-regulation of the expression of $\mathrm{C} 3$ and $\mathrm{CFB}$ by cSCC cells in culture and by tumor cells in cSCCs in vivo. The results also show that $\mathrm{C} 3$ and $\mathrm{CFB}$ regulate proliferation and migration of cSCC cells and promote growth of cSCC xenografts in vivo. These results identify $\mathrm{C} 3$ and $\mathrm{CFB}$ as tumor cell-associated biomarkers for development of cSCC and suggest them as biomarkers and potential therapeutic targets in recurrent and metastatic cSCCs.

\section{Materials and Methods}

\section{Ethical Issues}

Collection of normal skin and cSCC tissues and the use of archival tissue specimens was approved by the Ethics Committee of the Hospital District of Southwest Finland. The study was performed according to the Declaration of Helsinki. All patients gave written and informed permission before surgery, and the study was performed with the authorization of Turku University Hospital (Turku,
Finland). The experiments with mice were performed with the permission of the State Provincial Office of Southern Finland, according to institutional guidelines.

\section{Cell Cultures}

Human cSCC cell lines $(n=8)$ were established from surgically removed SCCs of skin. ${ }^{15,16}$ Five cSCC cell lines were derived from primary cSCCs (UT-SCC-12A, UT-SCC-91, UT-SCC-105, UT-SCC-111, and UT-SCC-118) and three from metastatic cSCCs (UT-SCC-7, UT-SCC-59A, and UTSCC-115). Cell lines were authenticated by STR DNA profiling. ${ }^{16}$ The spontaneously immortalized nontumorigenic human keratinocyte-derived cell line $\mathrm{HaCaT}^{16,17}$ and three Ha-ras - transformed tumorigenic HaCaT cell lines (A5, II-4, and RT3) ${ }^{18}$ were kindly provided by Dr. Norbert Fusenig (German Cancer Research Center, Heidelberg, Germany). A5 cells form benign, II-4 cells low-grade malignant, and RT3 cells high-grade malignant tumors in nude mice in vivo. ${ }^{19}$ NHEKs were cultured from nonmalignant skin of patients $(n=10)$ undergoing surgery for mammoplasty at Turku University Hospital. In addition, primary human epidermal keratinocytes (NHEK-PC) were acquired from PromoCell (Heidelberg, Germany). Cells were cultured, as previously described. ${ }^{13,14}$ To study the effect of inflammatory cytokines, cultures were maintained in serum-free Dulbecco's modified Eagle's medium for 24 hours, and then treated with $100 \mathrm{U} / \mathrm{mL}$ interferon (IFN)- $\gamma$ (Promega, Madison, WI) or $20 \mathrm{ng} / \mathrm{mL}$ tumor necrosis factor (TNF)- $\alpha$ (Sigma, St. Louis, MO) for 24 hours.

\section{Tissue RNA}

Normal human skin samples $(n=10)$ were obtained from the upper arm of healthy volunteers or during mammoplasty operation in Turku University Hospital. Primary cSCC $(n=6)$ samples were collected from surgically removed tumors in Turku University Hospital. ${ }^{15}$ Total RNA was isolated from the tissue samples and analyzed by realtime quantitative RT-PCR (RT-qPCR), as previously described. $^{20}$

\section{RT-qPCR}

The cell cultures were incubated in serum-free media for 24 hours before RNA isolation. Total RNA extraction was performed by using RNeasy Mini Kit (Qiagen, Chatworth, CA). cDNA was synthesized using $1 \mu \mathrm{g}$ of RNA treated with RQ1 DNase (M610A; Promega Corp., Madison, WI), random primers (C118A; Promega), M-MLV Reverse Transcriptase (M531A; Promega), and RNase H minus polymerase (M368B; Promega). The mRNA levels for $\mathrm{C} 3, \mathrm{CFB}$, and $\beta$-actin were determined by RT-qPCR using specific primers and dual-labeled fluorescent probes designed by RealTimeDesign software (Biosearch Technologies, Petaluma, CA) (Table 1). ${ }^{20}$ Murine functional 
Table 1 Primer and Probe Sequences Used for Quantitation of the mRNAs of Human C3, CFB, and $\beta$-Actin, and Murine C3, CFB Variant 1 , CFB Variant 2, and $\beta$-Actin with RT-qPCR

\begin{tabular}{|c|c|c|}
\hline Gene & Primer/probe & Sequence \\
\hline \multirow[t]{3}{*}{ Human $\mathrm{C3}$} & Forward primer & $5^{\prime}-$ GCCAAGACGAAGAGAA- $3^{\prime}$ \\
\hline & Reverse primer & 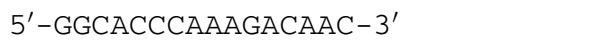 \\
\hline & Probe & $5^{\prime}-\mathrm{CCAGAAACAATGCCAGGACCTCGG-3^{ \prime }}$ \\
\hline \multirow[t]{3}{*}{ Human CFB } & Forward primer & $5^{\prime}$-CTGTGGCATGGTTTGG- $3^{\prime}$ \\
\hline & Reverse primer & $5^{\prime}-$ GGGCGAATGACTGAGAT-3' \\
\hline & Probe & $5^{\prime}-$ CACAGGAAGGGTACCGATTACCACA-3' \\
\hline Human $A C T B$ & Probe & $5^{\prime}-\mathrm{ATGCCCTCCCCCATGCCATCCTGCGT-3'}$ \\
\hline \multirow[t]{3}{*}{ Murine C3 } & Forward primer & $5^{\prime}$-GACGCCACTATGTCCATCCT-3' \\
\hline & Reverse primer & 5'-CCAGCAGTTCCAGGTCCTTTG-3' \\
\hline & Probe & $5^{\prime}$-CATCTCCATGATGACTGGCTTTGCTCC-3' \\
\hline Murine $C f b$ variant 1 & Forward primer & 5'-GGATGTCAAAGCTCTGTTTGTATC-3' \\
\hline Murine $C f b$ variant 2 & Probe & $5^{\prime}-$ TGAGCAAGGGAAGAGCCTGACTC-3' \\
\hline \multirow[t]{3}{*}{ Murine Actb } & Forward primer & $5^{\prime}-$ TGGCTCCTAGCACCATGAAGA-3' \\
\hline & Reverse primer & $5^{\prime}$-GTGGACAGTGAGGCCAGGAT-3' \\
\hline & Probe & 5'-CAAGATCATTGCTCCTCCTGAGCGCA-3' \\
\hline
\end{tabular}

ACTB, $\beta$-actin; CFB, complement factor B; RT-qPCR, real-time quantitative RT-PCR.

CFB consists of two isoforms that are coded by different variants, variants 1 and 2 . C3 and CFB mRNA levels were corrected for levels of $\beta$-actin mRNA. In each measurement, range of the threshold cycle values was $<5 \%$ of the mean and the samples were analyzed in duplicate.

\section{Western Blot Analysis}

Production of C3 and CFB by NHEKs, cSCC, and HaCaT cell lines was determined by Western blot analysis of aliquots of total cell lysates or conditioned media under nonreducing conditions using specific polyclonal goat anti-C3 and anti-CFB antibodies (both from Calbiochem, San Diego, CA). Equal protein loading was confirmed with $\beta$-actin antibody (A 1978; Sigma-Aldrich, St. Louis, MO). ${ }^{14}$

\section{Tissue Samples and Immunohistochemistry}

Altogether, 221 archival formalin-fixed, paraffin-embedded tissue samples from sporadic, UV-induced cSCC $(n=71$; mean age, 79 years; range, 45 to 102 years), cSCCIS (Bowen's disease; $n=69$; mean age, 79 years; range, 59 to 95 years), $\mathrm{AK}$ ( $n=63$; mean age, 78 years; range, 58 to 95 years), normal skin $(n=5)$ were obtained from the archives of the Department of Pathology, Turku University Hospital. In addition, recessive dystrophic epidermolysis bullosa (RDEB)-associated cSCC tissue samples $(n=11$; mean age, 33 years; range, 12 to 56 years) were used. ${ }^{21,22}$ Human tissue samples were assembled into tissue microarray blocks, as previously described, ${ }^{23}$ to enhance comparability. One representative cSCC sample was also analyzed as a whole tissue section. The sections were stained with goat polyclonal antibodies for $\mathrm{C} 3$ and $\mathrm{CFB}$ (both from Calbiochem) diluted in phosphate-buffered saline containing $1.5 \%$ horse serum. Immunostaining was performed with avidin-biotin-peroxidase complex technique (Vecta stain ABC Kit; Vector Laboratories, Inc., Burlingame, CA) in combination with diaminobenzidine and Mayer's hematoxylin (Sigma-Aldrich Chemie GmbH, Steinheim, Germany) as a counterstain. ${ }^{21}$ Negative control staining was performed by replacing the primary antibody with phosphate-buffered saline. The immunostainings of C3 and CFB were scored as negative $(-)$, weak $(+)$, moderate $(++)$, or strong $(+++)$, on the basis of the intensity of cell surface and cytoplasmic staining, by two independent observers (P.R. and M.K.). Whole slides of cSCC samples were digitally scanned using a Pannoramic 250 Slide Scanner (3DHistech, Budapest, Hungary).

\section{siRNA Knockdown of C3 and CFB Expression}

For siRNA knockdown of C3 and CFB, cSCC cells were grown to $50 \%$ confluency and transfected with siRNA targeting C3 (Hs_C3_8, 5' -ACGGTGGTGGCTATGGCTCTA3'; Hs_C3_6, 5'-CACGGAGAAGCGAATGGACAA-3'); Hs_C3_7 (5'-TAGGAACACCCTCATCATCTA-3' $\left.{ }^{\prime}\right)$; or CFB (Hs_CFB_1, 5'-CAGCGGCGAACGTGTCAGGAA3'; Hs_CFB_3, 5'-CCAGATGACGTCCCTCCTGAA-3'), or with negative control siRNA $(75 \mathrm{nmol} / \mathrm{L}$; all from Qiagen, New Delhi, India) using siLentFect Lipid Reagent (Bio-Rad Laboratories, Hercules, CA), as previously described. ${ }^{23}$ Cells were harvested at 72 hours, and the function 
of $\mathrm{C} 3$ and CFB siRNAs was verified by Western blot analysis. $\beta$-Actin served as loading control, and Western blot band intensities were quantified by ImageJ software version $1.47 \mathrm{v}\left(\mathrm{NIH}\right.$, Bethesda, MD; http://imagej.nih.gov/ij). ${ }^{24}$

\section{Cell Proliferation Assays}

cSCC cell cultures were transfected with $75 \mathrm{nmol} / \mathrm{L} \mathrm{C} 3$ siRNA, CFB siRNA, or negative control siRNA. Cells $(1.0 \times$ $10^{4}$ cells/well) were seeded onto 96 -well plates 24 hours after transfection. The number of viable cells was determined with WST-1 cell proliferation assay (Roche Diagnostics, Mannheim, Germany) at 0, 24, 48, and 72 hours. The experiment was performed with five to eight parallel wells in every time point with cSCC cell lines UT-SCC-12A and UT-SCC-7 for C3 siRNA, and with cSCC cell lines UT-SCC-12A and UT-SCC-91 for CFB siRNA. Activation of extracellular signal-regulated kinase (ERK) 1/2 was analyzed by Western blotting of the cell lysates with specific rabbit antibody for p44/42 mitogen-activated protein kinase (ERK1/2; 9102) and phospho-p44/42 mitogen-activated protein kinase (p-ERK1/2; 9101), both from Cell Signaling Technology (Beverly, MA).

\section{Cell Migration Assays}

cSCC cell cultures were transfected with $75 \mathrm{nmol} / \mathrm{L} \mathrm{C} 3$ siRNAs, CFB siRNAs, or control siRNA and incubated in complete growth medium for 24 hours to reach confluency. Cell division was inhibited with $1 \mathrm{mmol} / \mathrm{L}$ hydroxyurea (Sigma Aldrich) treatment in Dulbecco's modified Eagle's medium with $10 \%$ fetal calf serum for 16 hours. A scratch in the cell monolayer was generated with pipette tip and the incubation of cells was continued in Dulbecco's modified Eagle's medium with $1 \%$ fetal calf serum and $0.5 \mathrm{mmol} / \mathrm{L}$ hydroxyurea for 8 and 24 hours. Migration was analyzed with Olympus IX70 inverted microscope (Olympus Optical Co., Tokyo, Japan) The cell-free areas were measured from two to six areas in one well with ImageJ software version $1.47 \mathrm{v}^{24}$ in three parallel wells with two cSCC cell lines (UT-SCC-105 and UT-SCC-91).

\section{Human cSCC Xenografts}

Human cSCC xenografts were established, as described previously. ${ }^{14,25}$ UT-SCC-7 cell cultures were transfected with C3 siRNA_7 or control siRNA ( $n=8$ in both groups). Similarly, UT-SCC-91 cell cultures were transfected with CFB siRNA_1 or control siRNA. After 72 hours in C3 siRNA experiment, cSCC cells $\left(5 \times 10^{6}\right)$ and in CFB siRNA experiment, cSCC cells $\left(7 \times 10^{6}\right)$ in $100 \mu \mathrm{L}$ of phosphate-buffered saline were injected s.c. in the back of severe combined immunodeficiency (SCID/SCID) female mice (CB17/Icr-Prkdc ${ }^{\text {scid } / I c r I c o C r l) ~}$ ( $n=7$ to 8 for each group) (Charles River Laboratorie). The size of tumors was measured twice a week, and tumor volume was calculated with the formula: $\mathrm{V}=\left(\right.$ length $\times$ width $\left.^{2}\right) / 2$. $^{26}$
Tumors were harvested after 18 days for histologic analysis and immunohistochemistry, as previously described. ${ }^{14}$ Proliferating cells were detected with monoclonal human Ki-67 antibody (MIB-1; Dako, Glostrup, Denmark) and Mayer's hematoxylin was used as counterstain. The relative number of Ki-67-positive cells was determined by counting 400 to 1000 cells from all sections at $\times 20$ magnification using ImageJ software version $1.47 \mathrm{v} .^{24}$

\section{Mouse Skin Chemical Carcinogenesis}

Mouse skin carcinogenesis was induced in FVB/N HanHsd mice (maintained at the Laboratory Animal Center, University of Oulu, Oulu, Finland), as previously described. ${ }^{27}$ Skin tumor formation was induced first by topical administration of a single dose of 7,12-dimethylbenz $[\alpha]$ anthracene (100 $\mu \mathrm{g}$; DMBA; Sigma-Aldrich) in $100 \mu \mathrm{L}$ acetone on the shaved dorsal skin and then followed by treatment of skin with $5 \mu \mathrm{g}$ 12-O-Tetradecanoylphorbol-13-acetate (TPA) in $100 \mu \mathrm{L}$ acetone once a week for 20 weeks. The appearance of tumors was examined weekly and mice were sacrificed at week 32 or earlier if invasive carcinomas appeared, tumor size exceeded $10 \mathrm{~mm}$, or tumor load was excessive. DMBATPA-induced cSCC $(n=27)$, benign papillomas $(n=$ 17), hyperplastic TPA-treated $(n=6)$, acetone-treated ( $n=$ $2)$ and untreated normal $(n=8)$ skin samples were harvested and processed for histologic examination and RNA extraction, as previously described. ${ }^{27}$ The skin tissue samples were classified as hyperplasia, or well, moderately, or poorly differentiated SCC on the basis of analysis of hematoxylin and eosin-stained sections. Outliers have been deleted during statistical analysis.

\section{Statistical Analysis}

The statistical analyses were performed with the IBM SPSS Statistics software version 22.0 (IBM Corp., Armonk, New York, NY) to determine the significance of differences between two sample groups for RT-qPCR, Ki-67-positive staining, and proliferation and migration assays by MannWhitney $U$ test or $t$-test. Comparison of immunohistochemical (IHC) staining intensity was performed with $\chi^{2}$ test.

\section{Results}

\section{Expression of C3 and CFB Is Up-Regulated in cSCC Cells}

In our previous studies, marked up-regulation of the expression of $\mathrm{C} 3$ and CFB mRNA was noted in cSCC cell lines by microarray-based expression profiling and RNA sequencing-based whole transcriptome expression profiling. ${ }^{13,14}$ Herein, the mRNA levels of $\mathrm{C} 3$ and CFB were measured by RT-qPCR. The mean expression levels of C3 and CFB mRNAs were significantly higher in cSCC cells $(n=8)$, as compared to NHEKs $(n=11)$ (Figure 1A). No difference was noted in the expression levels of $\mathrm{C} 3 \mathrm{mRNA}$ 

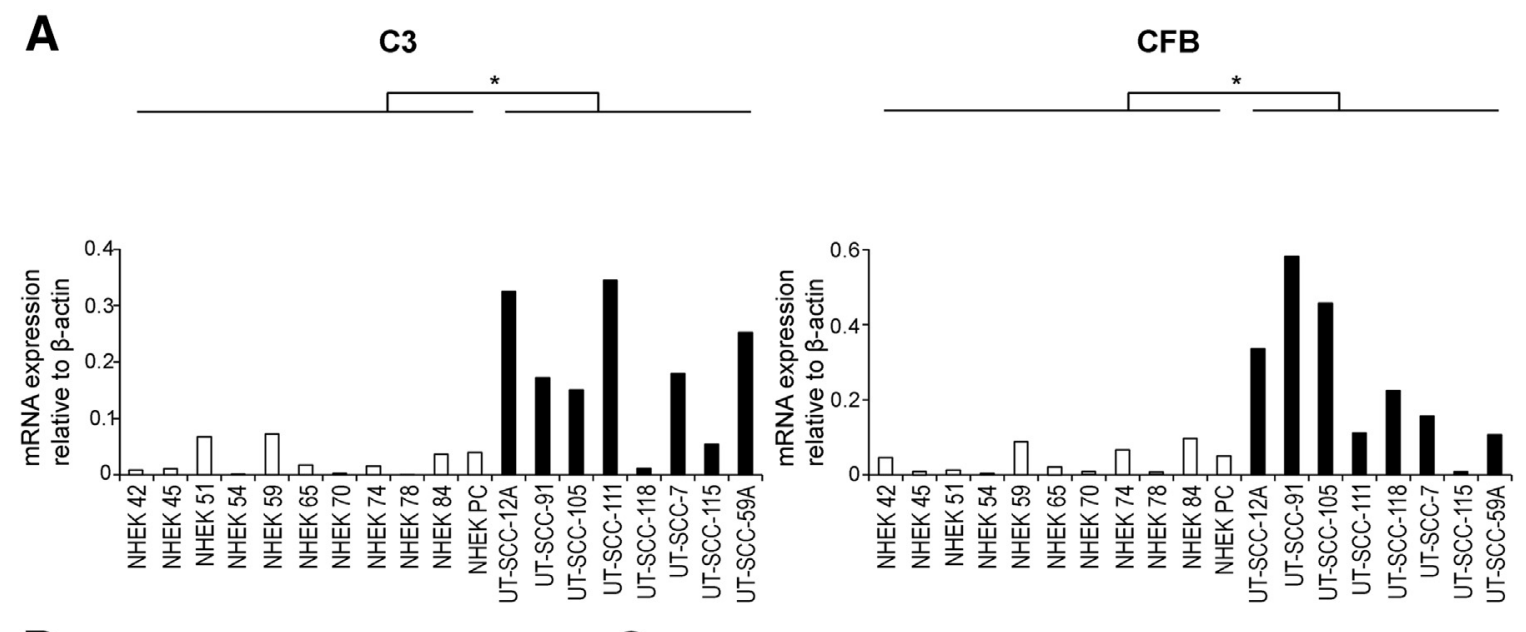

B
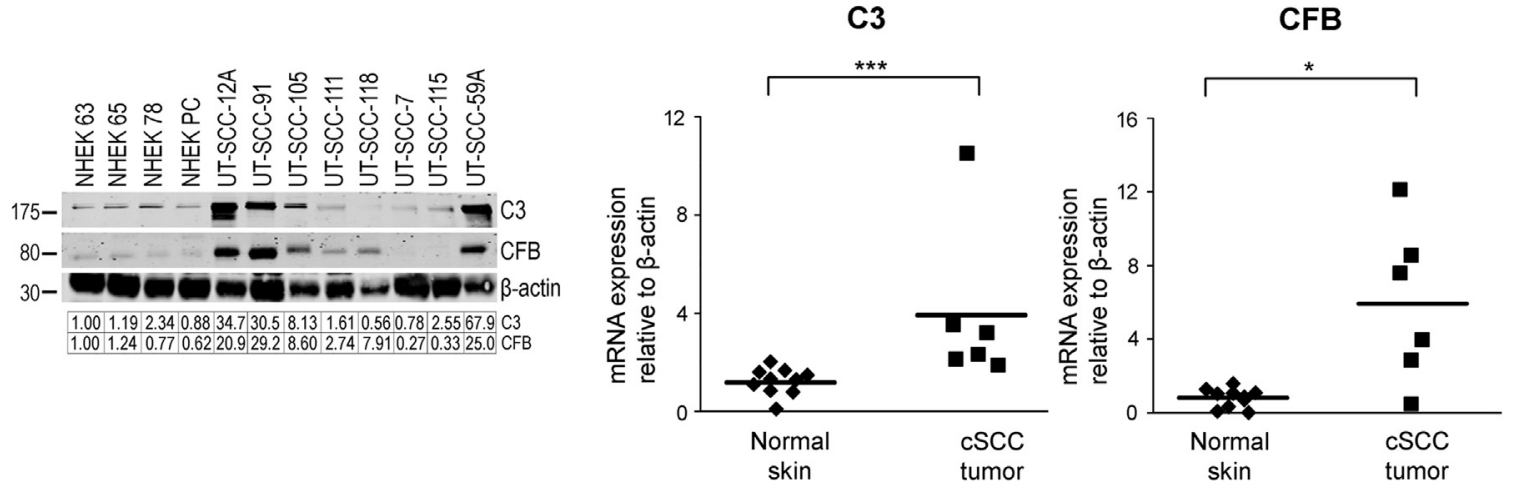

Figure 1 Expression of $\mathrm{C} 3$ and complement factor B (CFB) is up-regulated in cutaneous squamous cell carcinoma (CSCC) cells. A: C3 and CFB mRNA levels in normal human epidermal keratinocytes (NHEKs), primary, and metastatic CSCC cell lines were determined by real-time quantitative PCR (RT-qPCR) and the levels were corrected for $\beta$-actin mRNA levels in the same samples. B: The levels of C3 (185 kDa) and CFB (86 kDa) in NHEKs and cSCC cell lines were determined by Western blotting of conditioned media under nonreducing conditions. $\beta$-Actin in cell lysates was determined as a loading control. Migration positions of molecular weight markers are shown on the left. C3 and CFB levels were quantitated densitometrically and corrected for $\beta$-actin levels in the corresponding cell lysates. Values are shown below the Western blots relative to levels in NHEK 63 cells (1.00). C: Levels of C3 and CFB mRNA in normal skin and cSCC samples were analyzed by RT-qPCR and corrected for $\beta$-actin mRNA levels in the same samples. Horizontal bars indicate the mean values for each group. $n=11$ (A, NHEKs, and C, normal skin); $n=5$ (A, primary cSCC cell lines); $n=3$ (A, metastatic cSCC cell lines); $n=4$ (B, NHEKs); $n=8$ (B, CSCC cell lines); $n=6$ (C, cSCC samples). ${ }^{*}<<0.05,{ }^{*} * *<0.001$ (Mann-Whitney $U$ test).

between primary and metastatic cSCC cell lines. However, the expression level of CFB mRNA was higher in primary cSCC cell lines than in metastatic cSCC cell lines (Figure 1A). Using Western blot analysis, C3 (185 kDa) was detected in conditioned media of cSCC cell lines and NHEKs $(n=4)$, and the production of $\mathrm{C} 3$ was higher in five of eight cSCC cell lines than in NHEKs (Figure 1B). CFB (86 kDa) was detected in the conditioned media of most cSCC cell lines and the production of $\mathrm{CFB}$ was higher in six of eight cSCC cell lines than in NHEKs (Figure 1B). Elevated levels of $\mathrm{C} 3$ and $\mathrm{CFB}$ mRNAs were also detected in RNA from cSCC tumor tissue $(n=6)$, as compared with RNA from normal skin $(n=11)$ (Figure 1C).

Expression of C3 and CFB by Tumor Cells in cSCCs in Vivo

The expression of $\mathrm{C} 3$ and $\mathrm{CFB}$ in vivo was further analyzed by IHC using tissue microarrays consisting of a large panel of tissue samples representing different stages of epidermal carcinogenesis [namely, normal skin $(n=5)$, premalignant precursor lesion, AK $(n=63)$, carcinoma in situ (cSCCIS; $n=69)$, and $\operatorname{cSCC}(n=71)]$. For comparison, tissue samples of an aggressive form of $\operatorname{cSCC}, \operatorname{RDEBSCC}(n=11)$ were also included. Prominent tumor cell-specific staining intensity for C3 was noted in cSCCs (Figure 2, A and B). The staining for C3 was either cytoplasmic or on cell surface (Figure 2C). In addition, strong staining intensity for $\mathrm{C} 3$ was noted in tumor cells in RDEBSCC samples (Figure 2D). The staining for C3 was clearly weaker in cSCCIS and AK tissue samples than in cSCC tissue sections (Figure 2, F and G). Tumor cell-specific immunostaining for $\mathrm{C} 3$ was also noted ex vivo in xenografts established with human cSCC cells (UT-SCC-7) in SCID mice (Figure 2H). Semiquantitative analysis of IHC staining revealed strong $(+++)$ or moderate $(++)$ staining in most tissue sections in cSCC and RDEBSCC groups (Figure 2I). On the other hand, in AK and cSCCIS groups, the proportion of tissue sections with negative (-) and weak (+) staining was significantly higher than in cSCC or RDEBSCC samples. In normal skin group, staining of tissue samples for $\mathrm{C} 3$ was 

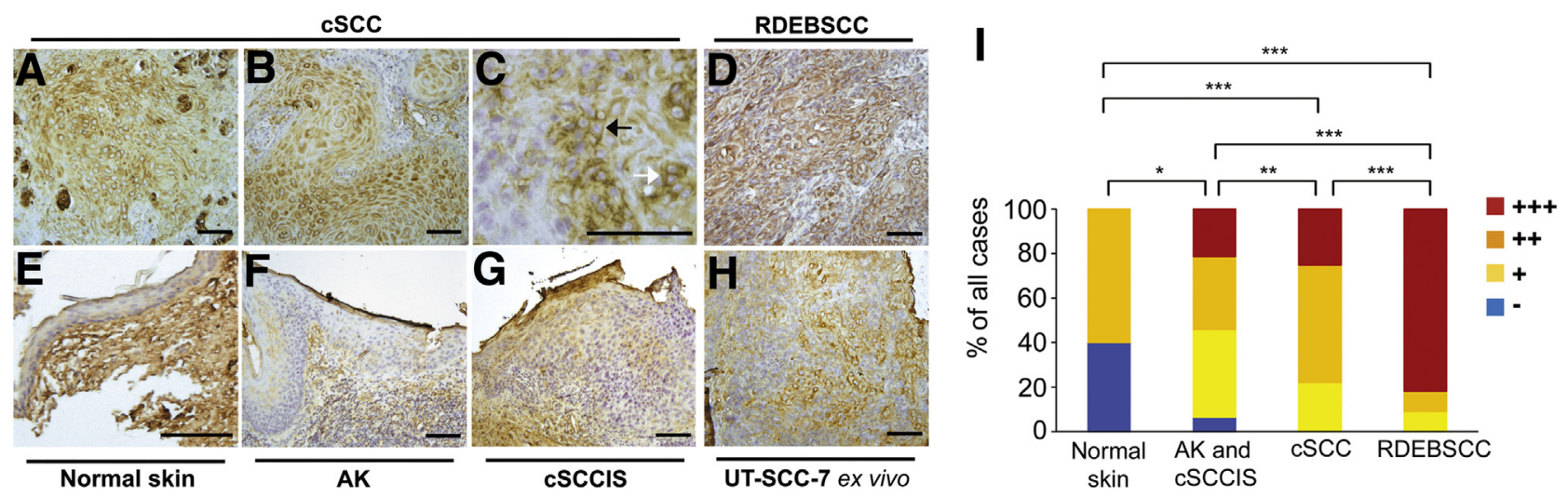

Figure 2 Expression of $\mathrm{C} 3$ by tumor cells in cutaneous squamous cell carcinoma ( $\mathrm{CSCC}$ ). A-H: Sections of tissue microarray blocks containing cSCC, aggressive forms of $\mathrm{CSCC}$, recessive dystrophic epidermolysis bullosa-associated CSCCs (RDEBSCC), normal skin, premalignant lesions [actinic keratosis (AK)], and CSCC in situ (CSCCIS), were stained with C3 antibody. In addition, sections of xenografts established in severe combined immunodeficiency mice with cSCC cell line (UT-SCC-7) ex vivo were stained with C3 antibody. The staining is moderate $(++)$ or strong $(+++)$ in moderately differentiated (Grade 2$)$ cSCC $(\mathbf{A})$ or well-differentiated (Grade 1) CSCC (B) and in RDEBSCC (D). C: The staining for C3 is seen in tumor cell cytoplasm (white arrow) or on cell surface (black arrow). E: Epidermal staining for $\mathrm{C} 3$ is absent $(-)$ in normal skin. In premalignant lesions (AK; $\mathbf{F}$ ) and in cSCCIS (G) the staining is weak or moderate. H: Tumor cells in CSCC xenografts stain strongly for C3. I: Semiquantitative analysis of C3 staining in normal skin, AK, CSCCIS, cSCC, and RDEBSCC. Tumor cell-specific immunostaining intensities of each section were scored as negative $(-)$, weak $(+)$, moderate $(++)$, and strong $(+++) . n=68(\operatorname{cSCC})$; $n=11(\mathrm{RDEBSCC})$; $n=5$ (normal skin); $n=63$ (AK); $n=59$ (cSCCIS). ${ }^{*} P<0.05,{ }^{* *} P<0.01$, and ${ }^{* *} P<0.001$ ( $\chi^{2}$ test). Scale bar $=100 \mu \mathrm{m}(\mathbf{A}-\mathbf{H})$.

negative or moderate (Figure 2, E and I). Expression of C3 was also analyzed in a representative whole tissue section of cSCC by IHC. Herein, more abundant staining for $\mathrm{C} 3$ was seen on surface or in the cytoplasm of tumor cells in well-differentiated parts of the cSCC, whereas in the adjacent AK the specific staining was weaker (Supplemental Figure S1).

Cytoplasmic staining for $\mathrm{CFB}$ was detected in tumor cells in cSCC tissue samples (Figure 3C) and was classified mainly as moderate or strong (Figure 3, A and B). As for
C3, the staining intensity for CFB was stronger in RDEBSCC tissue sections (Figure 3D). In premalignant lesions (AK) and in cSCCIS, staining for CFB was negative or weak in most tissue samples (Figure 3, F and G). Normal skin was negative or stained weakly for CFB (Figure 3E). No correlation was detected between staining for CFB and the degree of inflammation. Tumor cell-specific immunostaining for CFB was also noted ex vivo in tissue sections of the xenograft tumors established with human $\mathrm{cSCC}$ cells

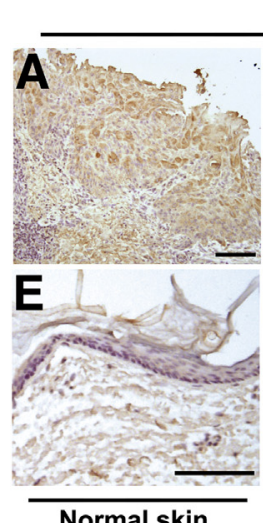

Normal skin
cSCC
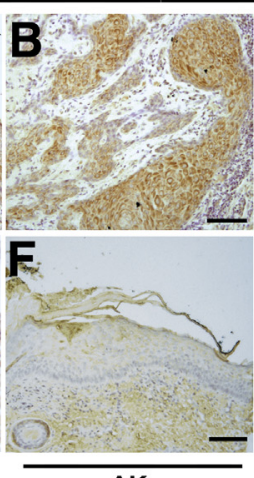

AK
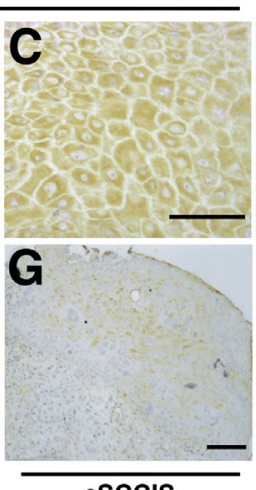

cSCCIS
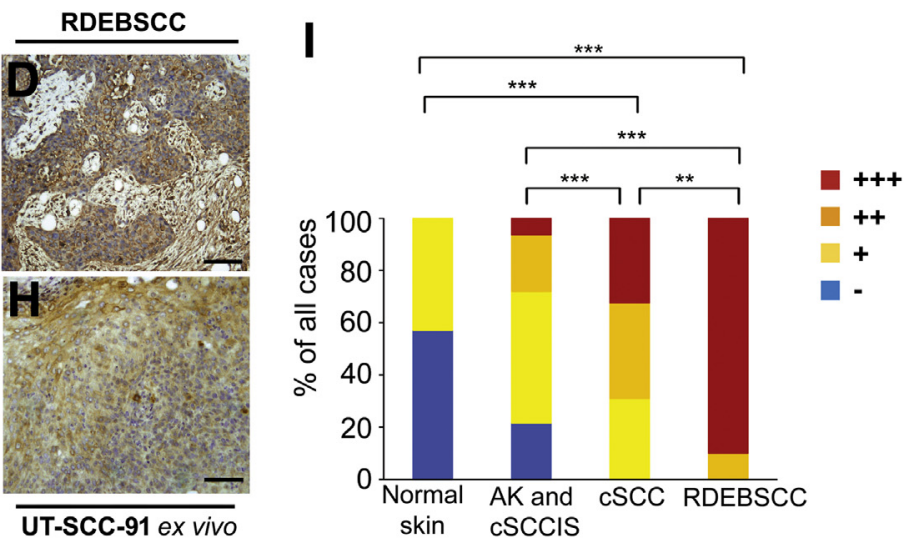

Figure 3 Expression of complement factor B (CFB) by tumor cells in cutaneous squamous cell carcinoma (CSCC). A-H: Sections of tissue microarray blocks containing CSCC, aggressive forms of CSCC, recessive dystrophic epidermolysis bullosa-associated CSCCS (RDEBSCC), normal skin, premalignant AK, and CSCCIS were stained with CFB antibody. In addition, xenografts established in SCID mice with CSCC cell line (UT-SCC-91) ex vivo were stained for CFB. The staining of tumor cells for CFB was moderate $(++)$ in well-differentiated (Grade 1) CSCC (A) and strong $(+++)$ in poorly differentiated (Grade 3$)$ (B) cSCC. C: The staining for CFB was detected in cytoplasm of tumor cells. D: Strong staining for CFB is detected in RDEBSCC. E: In normal skin the staining is negative (-). In premalignant lesions (AK; F) and CSCCIS (G) the staining is weak $(+)$. H: Tumor cells in CSCC xenografts stain strongly $(+++)$ for CFB. I: Semiquantitative analysis of CFB staining in normal skin, AK, CSCCIS, CSCC, and RDEBSCC. The staining was scored negative $(-)$, weak $(+)$, moderate $(++)$, or strong $(+++)$ by the specific staining intensity of tumor cells. $n=71$ (cSCC); $n=10$ (RDEBSCC); $n=5$ (normal skin); $n=56$ (premalignant AK); $n=69$ (cSCCIS). ${ }^{* * P}<0.01,{ }^{* * *} P<0.001$ ( $\chi^{2}$ test). Scale bar $=100 \mu \mathrm{m}(\mathbf{A}-\mathbf{H})$. 

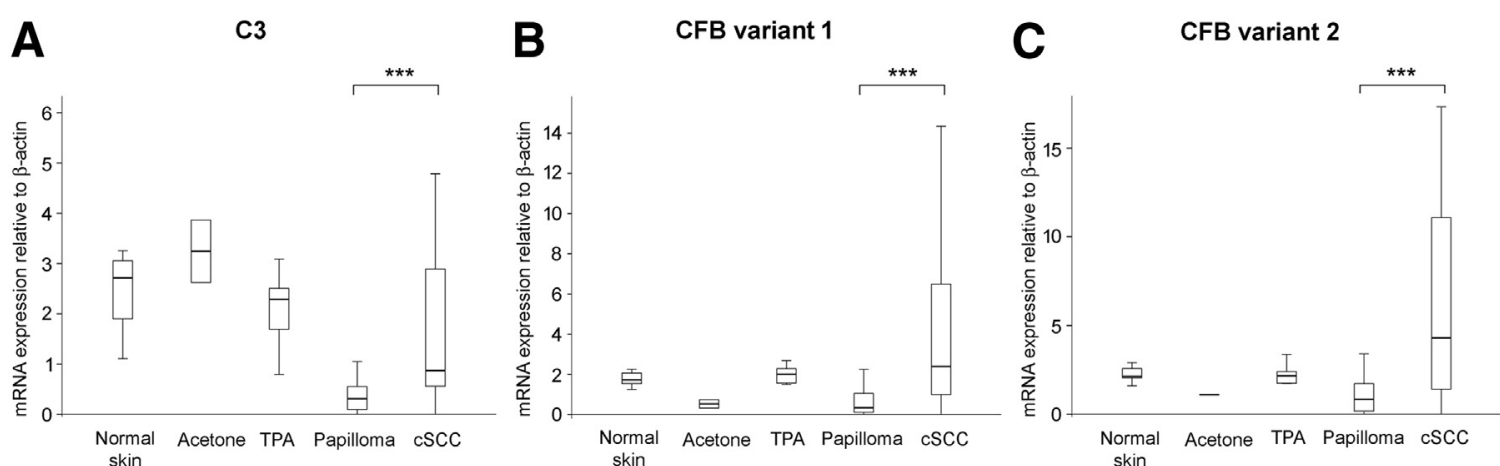

Figure 4 Expression of $\mathrm{C} 3$ and complement factor $\mathrm{B}$ (CFB) in chemically induced mouse cutaneous squamous cell carcinoma (CSCC). The mRNA levels for mouse C3, CFB variant 1, and CFB variant 2 in mouse normal skin, acetone-treated skin, TPA-treated hyperplastic skin, papilloma, and DMBA-TPA-induced CSCC were determined by real-time quantitative RT-PCR and corrected for the levels of $\beta$-actin mRNA in the same samples. Horizontal bars in box plots indicate median, boxes indicate interquartile range, and whiskers indicate lowest and highest values within 1.5 times the interquartile range for each group. Outliers have been deleted. A: The mRNA levels for mouse C3 in mouse normal skin, acetone-treated skin, TPA-treated hyperplastic skin, papilloma, and DMBATPA-induced CSCC. The expression of C3 mRNA in mouse CSCC is significantly higher than in benign papilloma. B: The mRNA levels for mouse CFB variant 1 in mouse normal skin, acetone-treated skin, TPA-treated hyperplastic skin, papilloma, and DMBA-TPA-induced cSCC. The expression of CFB variant 1 mRNA is significantly higher in CSCC than in papilloma. C: The mRNA levels of CFB variant 2 in mouse normal skin, acetone-treated skin, TPA-treated hyperplastic skin, papilloma, and DMBA-TPA-induced CSCC. The expression of CFB variant 2 mRNA is significantly higher in CSCC than in papilloma. $n=8$ (A, normal skin); $n=2$ (A-C, acetone-treated skin); $n=6$ (A-C, TPA-treated hyperplastic skin); $n=16$ (A and C, papilloma); $n=25$ (A and B, DMBA-TPA-induced cSCC); $n=7$ (B and C, normal skin); $n=17$ (B, papilloma); $n=23$ (C, DMBA-TPA-induced CSCC). ${ }^{* *} P<0.001$.

(UT-SCC-91) in SCID mice (Figure 3H). Semiquantitative analysis revealed strong or moderate staining for CFB in most tissue sections in cSCC and RDEBSCC groups (Figure 3I). In comparison, the proportion of negative (-) and weak $(+)$ staining for CFB was significantly higher in $\mathrm{AK}$ and cSCCIS groups than in cSCC or RDEBSCC tissues. In normal skin group, staining of tissue samples for CFB was weak or negative (Figure 3, E and I). Expression of CFB was also analyzed in a whole cSCC tissue section by IHC. Herein, the staining was stronger on surface or in the cytoplasm of tumor cells in well-differentiated parts of the cSCC, whereas in the adjacent tissue representing AK the staining was weak (Supplemental Figure S1).

\section{Expression of C3 and CFB in Chemically Induced Mouse CSCC}

To further examine the expression of $\mathrm{C} 3$ and $\mathrm{CFB}$ during $\mathrm{CSCC}$ growth, mouse model of chemically induced cSCC was used. $^{15,27}$ Total RNA samples from normal skin $(n=8)$, acetone-treated skin $(n=2)$, TPA-treated hyperplastic skin $(n=6)$, papilloma $(n=17)$, and DMBA-TPA-induced cSCC $(n=25)$ were analyzed by RT-qPCR for the mRNA levels of $\mathrm{C} 3$ and two murine variants of $\mathrm{CFB}$, variants 1 and 2. The results showed that the expression of mRNAs for $\mathrm{C} 3$ and CFB variants 1 and 2 was significantly higher in mouse cSCCs than in nonmalignant papilloma tissues (Figure 4).
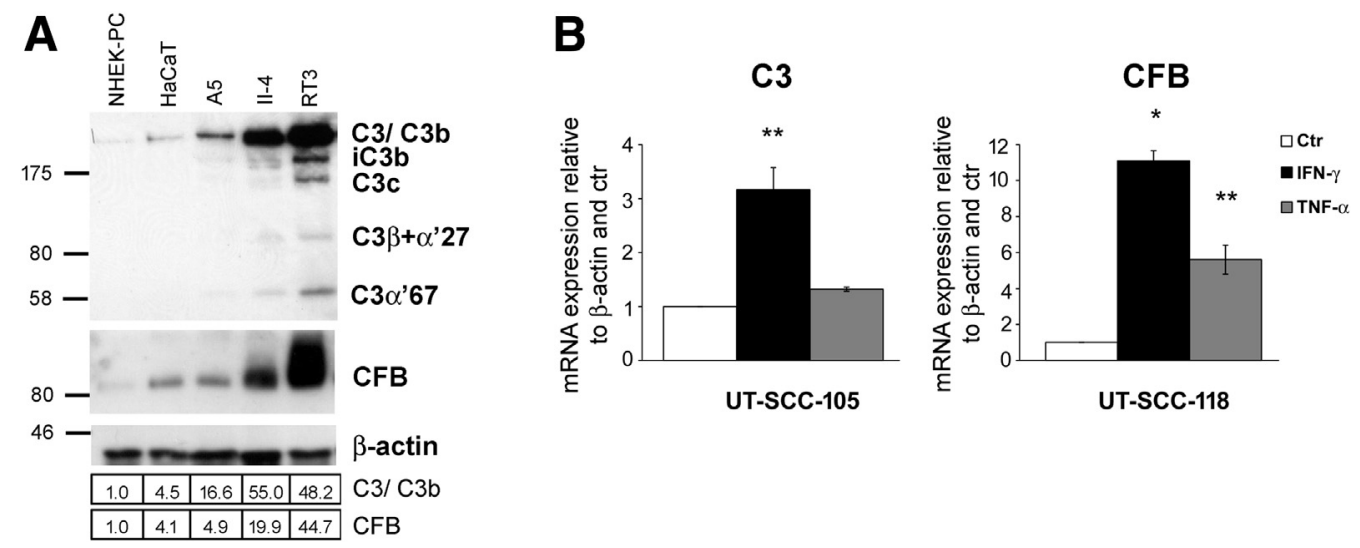

Figure 5 Regulation of $\mathrm{C} 3$ and complement factor B (CFB) expression in HaCaT and Ha-ras-transformed HaCaTs and cutaneous squamous cell carcinoma (CSCC) cells. A: The presence of C3/C3b (193/184 kDa), and C3 cleavage products iC3b (182 kDa), C3c (142 kDa), C3 $\beta+\alpha^{\prime} 27$ (102 kDa), C3 $\alpha^{\prime} 67$ (67 kDa), and CFB $(86 \mathrm{kDa})$ in medium samples of NHEK-PC, HaCaT, and Ha-ras-transformed HaCaT cell cultures (A5, II-4, and RT3) was analyzed by Western blotting under nonreducing conditions. Cell lysate $\beta$-actin was determined as loading control. Migration positions of molecular weight markers are shown on the left. The levels of C3 and CFB were quantitated densitometrically and corrected for $\beta$-actin levels in the corresponding cell lysates. Values are shown below the Western blots and relative to the levels in NHEK-PC cells (1.0). B: Primary CSCC cell lines (UT-SCC-105 and -118) were treated with $100 \mathrm{U} / \mathrm{mL}$ interferon (IFN)- $\gamma$ and $20 \mathrm{ng} / \mathrm{mL}$ tumor necrosis factor (TNF)- $\alpha$ for 24 hours. Levels of C3 and CFB mRNA were measured by real-time quantitative RT-PCR and corrected for the levels of $\beta$-actin mRNA in the same samples. Data are expressed as means $\pm \mathrm{SD}(\mathbf{B}) .{ }^{*} P<0.05,{ }^{*} P<0.01$ (t-test). Ctr, control. 

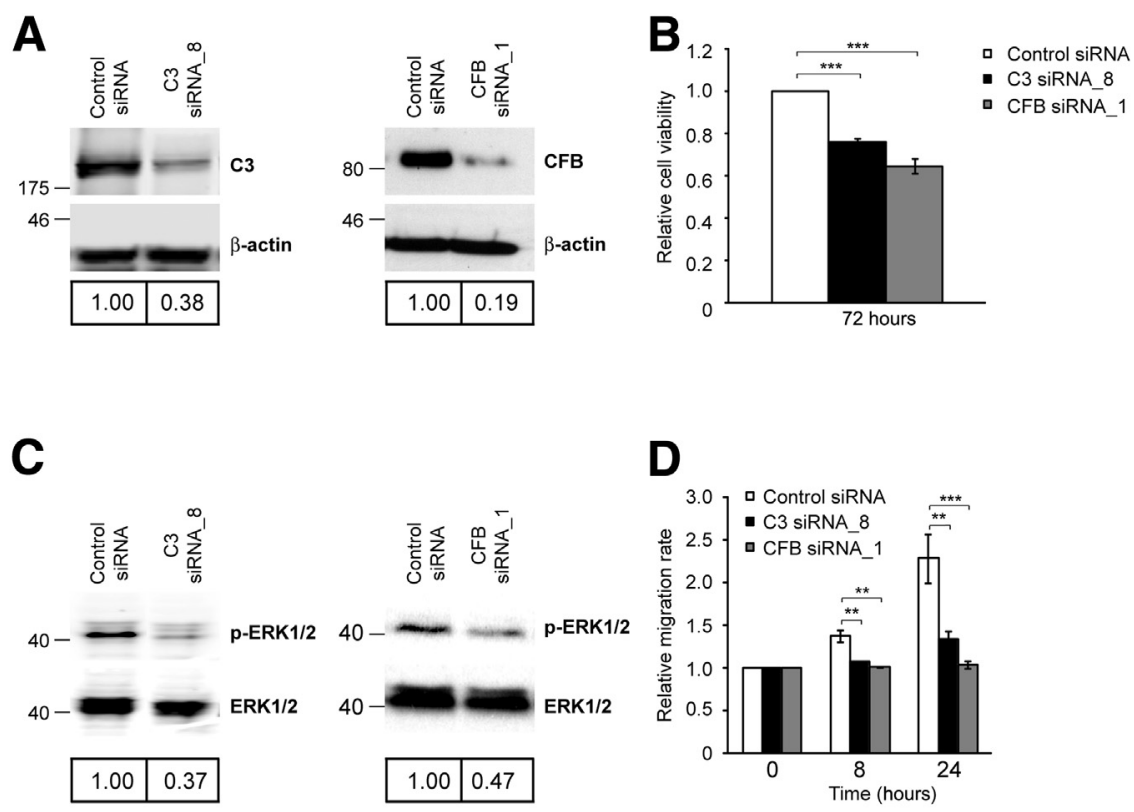

\section{E}

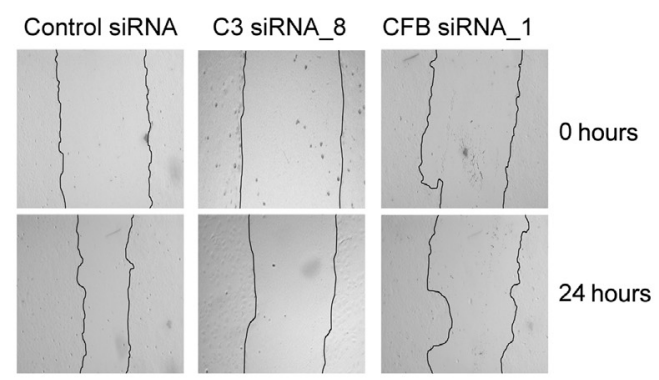

Figure 6 Knockdown of $C 3$ and complement factor B (CFB) inhibits proliferation and migration of cutaneous squamous cell carcinoma cells (CSCC). A: $\mathrm{C} 3$ and $\mathrm{CFB}$ were knocked down by specific siRNAs (C3 siRNA_8 or CFB siRNA_1; $75 \mathrm{nmol} / \mathrm{L}$ ) in primary CSCC cells (UT-SCC-12A) and parallel cultures were transfected with control siRNA. Cell lysates were analyzed for the levels of C3 and CFB with Western blotting 72 hours after transfections with siRNA. The levels were quantitated densitometrically and corrected for $\beta$-actin levels in the same sample. Values are shown below the Western blots relative to the levels in control siRNA-transfected cultures (1.00). B: CSCC cells (UT-SCC-12A) were transfected with 75 nmol/L control siRNA, C3 siRNA_8, or CFB siRNA_1. The number of viable cells was determined at 72 hours using WST- 1 assay. C: CSCC cell (UT-SCC-12A) lysates were analyzed for the levels of phosphorylated extracellular signal-regulated kinase-1/2 (p-ERK1/2) and total ERK1/2 by Western blotting 48 hours after siRNA transfection. Levels of $p$-ERK1/2 were quantitated by densitometry and corrected for the levels of total ERK $1 / 2$ in the same samples. Values are shown below the Western blots relative to the levels in control siRNA transfected cultures (1.00). D: cSCC cells (UT-SCC-105) were transfected with $75 \mathrm{nmol} /$ L control siRNA, C3 siRNA_8, or CFB siRNA_1 and incubated for 24 hours. The cultures were then treated with $1 \mathrm{mmol} / \mathrm{L}$ hydroxyurea for 16 hours to inhibit cell proliferation. A scratch was generated in the cell monolayer by pipette tip and incubation was continued in Dulbecco's modified Eagle's medium with $1 \%$ fetal calf serum and $0.5 \mathrm{mmol} / \mathrm{L}$ hydroxyurea for 8 and 24 hours. Quantitation of the relative migration rate for C3 and CFB siRNA transfected cultures. E: Representative images at time points 0 and 24 hours are shown. Data are expressed as means \pm SEM (D). $n=7$ to 8 parallel wells (B); $n=3$ (D). ${ }^{* *} P<0.01,{ }^{* * *} P<0.001$ ( $t$-test).

\section{Expression of C3 and CFB in Tumorigenic Ha-ras-Transformed HaCaT Cells}

To further investigate the significance of $\mathrm{C} 3$ and $\mathrm{CFB}$ in the epidermal carcinogenesis, the expression of $\mathrm{C} 3$ and CFB was determined in immortalized nontumorigenic keratinocyte-derived cell line ( $\mathrm{HaCaT})$ lacking functional p53, and in three Ha-ras -transformed tumorigenic HaCaTderived cell lines (A5, II-4, and RT3). ${ }^{19}$ Production of C3 and CFB was elevated in invasive tumorigenic cell line II-4 and was highest in metastatic cell line RT3 (Figure 5A). As shown previously, ${ }^{13,14}$ the $\mathrm{C} 3$ inhibitors complement factors $\mathrm{H}$ and I are expressed by cSCC cells. The function of these inhibitors is seen by the presence of $\mathrm{C} 3$ cleavage fragments in the media of RT3 cells (Figure 5A).

\section{Regulation of C3 and CFB Expression in CSCC Cell Lines}

To examine the regulation of $\mathrm{C} 3$ and CFB expression, cSCC cell line cultures were treated with inflammatory cytokines IFN- $\gamma$ or TNF- $\alpha$. In primary cSCC cell line (UT-SCC-105), the mRNA expression of $\mathrm{C} 3$ was up-regulated by IFN- $\gamma$
(Figure 5B). The expression of CFB mRNA was up-regulated by IFN- $\gamma$ and TNF- $\alpha$ in another primary cSCC cell line (UT-SCC-118) (Figure 5B).

\section{C3 and CFB Regulate cSCC Cell Proliferation and Migration}

To examine the functional roles of $\mathrm{C} 3$ and $\mathrm{CFB}$ in cSCC cells, their expression was silenced by specific siRNAs (Figure 6A and Supplemental Figure S2A). Significant reduction in the number of viable cSCC cells was noted 72 hours after transfection with $\mathrm{C} 3$ siRNAs and CFB siRNAs (Figure 6B and Supplemental Figure S2B). The inhibitory effect of C3 and CFB knockdown on cSCC cell proliferation was preceded by inhibition of ERK1/2 activation noted 48 hours after transfection with specific siRNAs (Figure 6C and Supplemental Figure S2C). Moreover, the migration rate of cSCC cells was significantly reduced after C3 or CFB knockdown (Figure 6, D and E, and Supplemental Figure S2, $\mathrm{D}$ and $\mathrm{E})$. Similar results on cell migration were obtained with another cell line (UT-SCC-91; data not shown). 
A

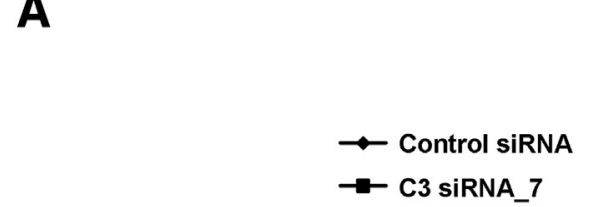

B
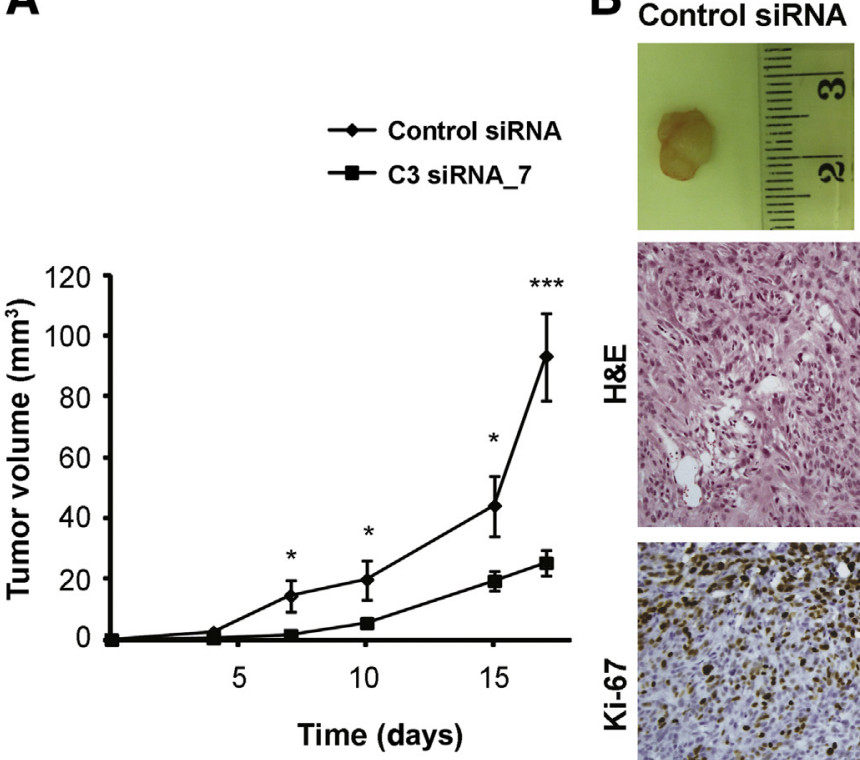

C

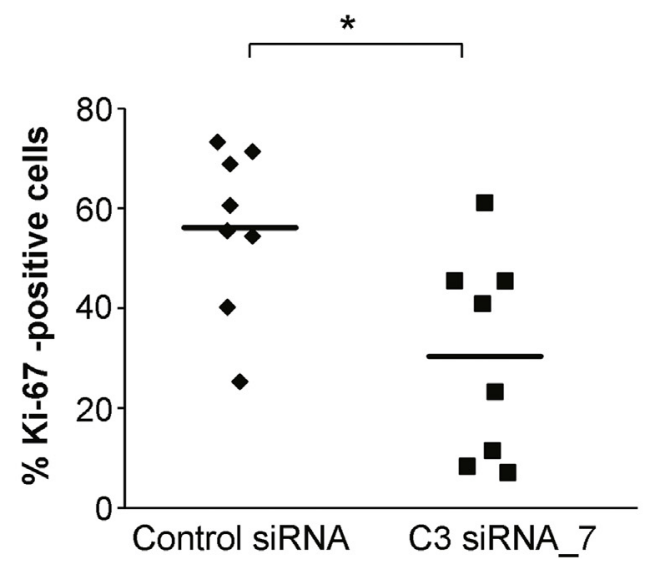

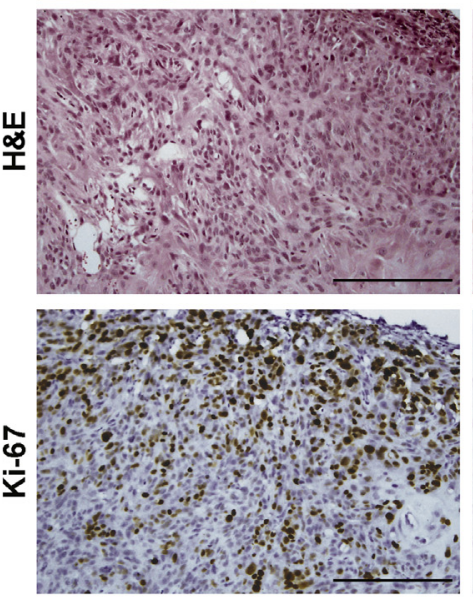
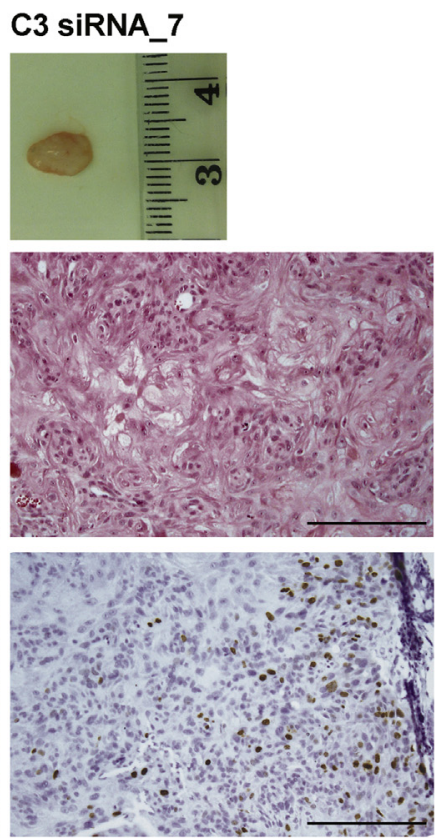

Figure 7 Knockdown of $\mathrm{C} 3$ suppresses growth of cutaneous squamous cell carcinoma (CSCC) in vivo. A: Metastatic CSCC cells (UT-SCC-7) were transfected with C3 siRNA_7 or control siRNA and incubated for 72 hours. Cells $\left(5 \times 10^{6}\right)$ were injected s.c. in the back of SCID mice and the size of tumors was measured twice a week. $t$-Test was used. B: The xenograft tumors were harvested after 18 days and histologic analysis performed in tumor sections stained with hematoxylin and eosin (H\&E). Proliferating cells in xenografts were detected by immunohistochemistry for Ki-67 with Mayer's hematoxylin as counterstain. Representative staining from each group are shown. C: The relative number of $\mathrm{Ki}-67-$ positive cells was determined by counting 400 to 1000 cells at $\times 20$ magnification in all tumor sections using digital imaging. Horizontal bars indicate the mean values for each group (Mann-Whitney $U$ test). Data are expressed as means $\pm \operatorname{SEM}(\mathbf{A}) \cdot n=8(\mathbf{A}$ and $\mathbf{C}) .{ }^{*} P<0.05,{ }^{* * *} P<0.001$. Scale bar $=200 \mu \mathrm{m}(\mathbf{B})$.

\section{C3 and CFB Regulate CSCC Growth in Vivo}

The roles of $\mathrm{C} 3$ and $\mathrm{CFB}$ on cSCC growth was examined in vivo in a xenograft model. Cultures of metastatic cSCC cells (UT-SCC-7) were transfected with $\mathrm{C} 3$ and control siRNA in parallel, incubated for 72 hours, and injected $\left(5 \times 10^{6}\right)$ s.c. into the back of SCID/SCID mice. Determination of the size of xenografts showed that the growth of cSCC xenograft tumors with C3 knockdown was significantly reduced, as compared to control siRNA tumors (Figure 7A). Moreover, histologic analysis of xenografts harvested 18 days after implantation showed that the tumors in C3 knockdown group were less cellular than the control tumors (Figure 7B). In addition, the relative number of proliferating Ki-67-positive cells was lower in $\mathrm{C} 3$ knockdown tumors (Figure 7, B and C).

The role of CFB on cSCC growth in vivo was similarly examined in xenograft model, as above. Primary cSCC cells
(UT-SCC-91) were cultured and transfected with CFB and control siRNA in parallel, and transfected cells $\left(7 \times 10^{6}\right)$ were injected s.c. into the back of SCID/SCID mice. The growth of cSCC xenograft tumors established with cSCC cells with CFB knockdown was significantly reduced, as compared to control tumors established with control siRNA-transfected cSCC cells (Figure 8A). Histologic analysis of the xenografts showed that the morphology of CFB knockdown tumors was clearly different from control xenograft tumors (Figure 8B). The tumor cells in CFB knockdown xenografts were arranged into tight groups, whereas in control siRNA tumors the tumor cells were bigger and formed larger groups. The stromal compartment of CFB knockdown tumors was also less cellular than the stroma of control siRNA xenografts (Figure 8B). In addition, the relative number of proliferating $\mathrm{Ki}-67-$ positive cells was significantly reduced in CFB knockdown tumors (Figure 8C). 
A
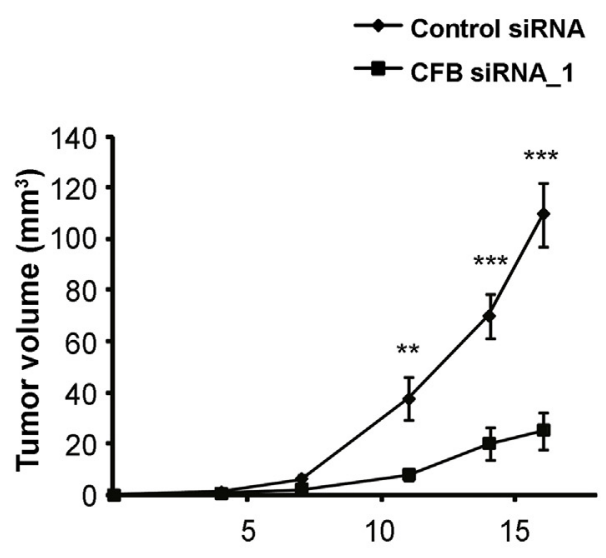

Time (days)

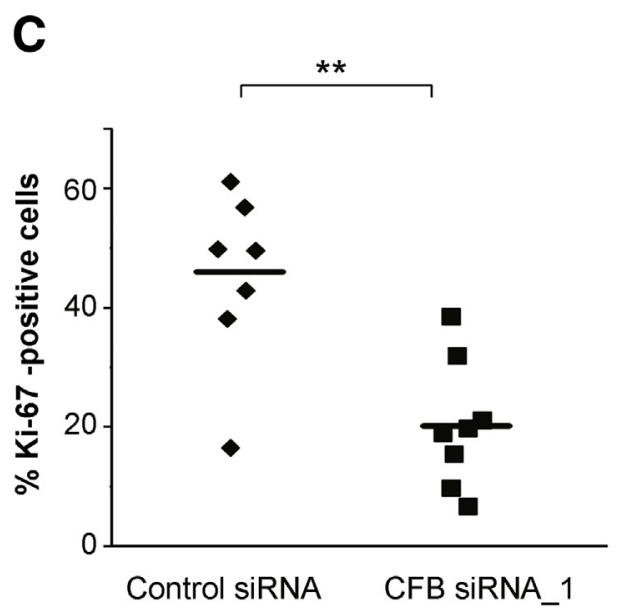

B

Control siRNA
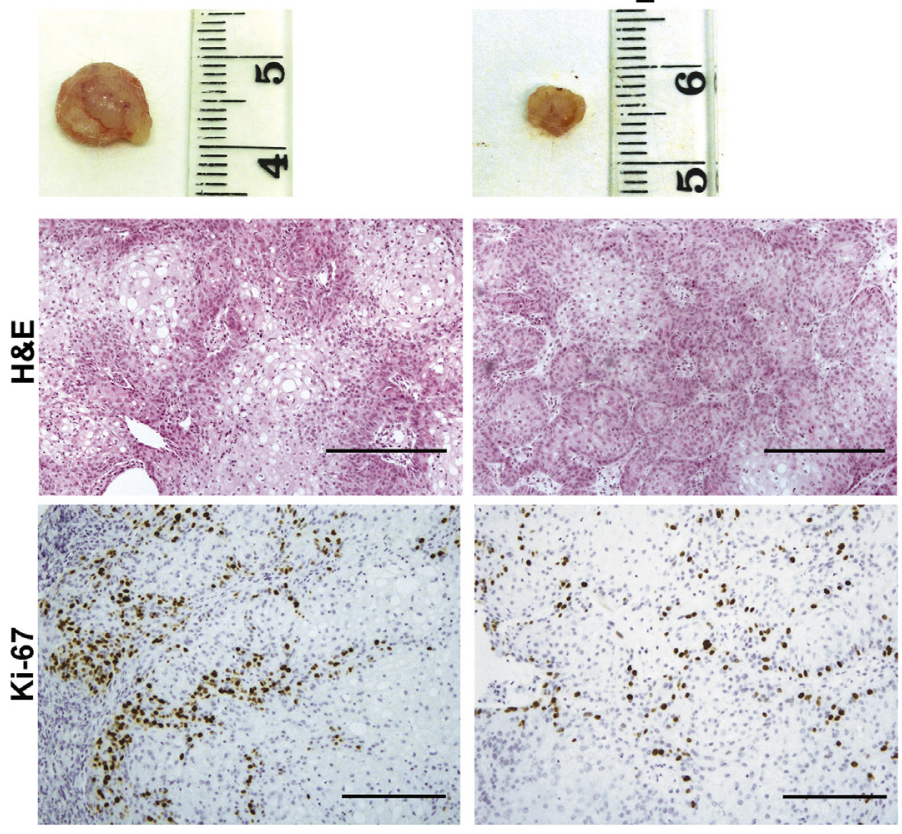

Figure 8 Knockdown of complement factor B (CFB) suppresses growth of cutaneous squamous cell carcinoma (CSCC) in vivo. A: Primary cSCC cells (UTSCC-91) were transfected with CFB siRNA_1 or control siRNA and incubated for 72 hours. Cells $\left(7 \times 10^{6}\right)$ were injected s.c. in the back of SCID mice and the size of tumors was measured twice a week. B: The xenograft tumors were harvested after 18 days and histologic analysis of the tumor sections stained with hematoxylin and eosin (H\&E) was performed. Proliferating cells in xenografts were detected by immunohistochemistry for Ki- 67 with Mayer's hematoxylin as counterstain. Representative staining from each group are shown. C: The relative number of Ki-67-positive cells was determined by counting 400 to 1000 cells at $\times 20$ magnification in all tumor sections using digital imaging. Horizontal bars indicate the mean values for each group, control siRNA and CFB siRNA (Mann-Whitney $U$ test). Data are expressed as means \pm SEM (A). $n=8$ (A and C, CFB siRNA_1); $n=7$ (A and C, control siRNA). ${ }^{* *} P<0.01$, $* * * P<0.001$. Scale bar $=200 \mu \mathrm{m}$ (B).

\section{Discussion}

The results of this study demonstrate elevated expression of $\mathrm{C} 3$ and CFB mRNA in cSCC cells in culture and in vivo compared to NHEKs and normal intact skin, respectively. In addition, increased production of $\mathrm{C} 3$ and CFB by cSCC cells in culture was noted (Figure 1). Analysis of tissue microarrays consisting of a large panel of cSCC, cSCCIS, $\mathrm{AK}$, and normal skin by IHC revealed specific cytoplasmic staining for $\mathrm{C} 3$ and $\mathrm{CFB}$ in tumor cells in cSCCs in vivo. In addition, staining for $\mathrm{C} 3$ was noted on cSCC cell surface in tumors in vivo (Figure 2). Immunostaining for $\mathrm{C} 3$ was moderate or strong in most cSCCs and in an aggressive form of cSCC, RDEBSCC, staining for C3 was mainly strong. No tumors with negative staining for $\mathrm{C} 3$ were detected in cSCC or in RDEBSCC groups, whereas in premalignant lesions, actinic keratosis (AK) and in situ tumors (cSCCIS), weak or negative staining was noted. In normal intact skin, staining for $\mathrm{C} 3$ was negative in almost half of the cases. Similarly, staining for CFB was stronger in CSCC tumors compared to cSCCISs, AK, and normal skin (Figure 3). In almost all RDEBSCC samples, staining for CFB was strong, and in most cases in cSCC group, staining was strong or moderate. No negative staining for CFB was noted in any cSCC or RDEBSCC tissue sample. Only few samples of $\mathrm{AK}$ and cSCCIS stained strongly for CFB, and most stained weakly or were negative. Most normal skin samples were also negative for CFB. In summary, the results of IHC staining suggest $\mathrm{C} 3$ and $\mathrm{CFB}$ as biomarkers for development of cSCC to the invasive stage.

Additional evidence for the roles of $\mathrm{C} 3$ and CFB in cutaneous carcinogenesis was obtained with examination of chemically induced mouse cSCCs. The results showed that the mean expression levels of $\mathrm{C} 3$ and $\mathrm{CFB}$ mRNAs were 
higher in mouse cSCCs than in papillomas, TPA-treated hyperplastic skin, or normal skin (Figure 4). Together, these observations show that the expression of $\mathrm{C} 3$ and $\mathrm{CFB}$ is significantly up-regulated in invasive cSCCs in vivo, suggesting roles for them in the growth of cSCC. Our findings are supported by previous observations showing expression of $\mathrm{C} 3$ and CFB by tumor cells in rhabdomyosarcoma ${ }^{27,28}$ and glioma ${ }^{29}$ and CFB in pancreatic ductal adenocarcinoma. ${ }^{30} \mathrm{C} 3$ has been suggested as a prognostic factor in non-small-cell lung cancer. ${ }^{31}$ In ovarian cancer, high $\mathrm{C} 3$ or C5R mRNA levels were associated with reduced survival and were suggested as tumor-derived complement proteins promoting tumor growth. ${ }^{32}$

In Ha-ras-transformed $\mathrm{HaCaT}$ cell lines representing different stages of keratinocyte carcinogenesis, ${ }^{19}$ the expression of $\mathrm{C} 3$ and $\mathrm{CFB}$ was associated with the tumorigenic potential (Figure 5A). The basal expression of $\mathrm{C} 3$ and $\mathrm{CFB}$ was low in parental $\mathrm{HaCaT}$ cells and in benign tumorigenic Ha-ras-transformed HaCaT cell line (A5). In contrast, the expression of $\mathrm{C} 3$ and $\mathrm{CFB}$ was clearly higher in the tumorigenic cell line II-4 and in the most aggressive invasive tumorigenic cell line RT3. These findings reveal that the basal expression of $\mathrm{C} 3$ and $\mathrm{CFB}$ is not induced by p53 inactivation or ras-transformation alone, but that other mechanisms are obviously required. Our results also show that the level of $\mathrm{C} 3$ expression is enhanced by IFN- $\gamma$ in cSCC cells and that the basal CFB expression is upregulated by both IFN- $\gamma$ and TNF- $\alpha$ in cSCC cells (Figure 5B). In previous studies, IFN- $\gamma$ has been shown to up-regulate $\mathrm{C} 3$ and CFB expression and TNF- $\alpha$ to upregulate $\mathrm{C} 3$ expression in keratinocytes. ${ }^{10}$ These results show that $\mathrm{C} 3$ and $\mathrm{CFB}$ expression by cSCC cells is susceptible to regulation by inflammatory cytokines present in the tumor microenvironment of cSCCs.

Silencing of $\mathrm{C} 3$ and $\mathrm{CFB}$ expression in cSCC cells revealed that both $\mathrm{C} 3$ and $\mathrm{CFB}$ promote proliferation and migration of cSCC cells (Figure 6). Additional functional in vivo studies using xenograft model of human $\mathrm{CSCC}$ in SCID mice showed that knockdown of C3 or CFB resulted in significant delay in cSCC xenograft growth and in reduction in the number of proliferating cells in the tumors (Figures 7 and 8). These observations are in accordance with our finding that knockdown of $\mathrm{C} 3$ and CFB potently inhibited activation of ERK1/2 and proliferation of cSCC cells (Figure 6). C3 cleavage product C3a has been shown to activate mitogenic signaling pathways (phosphatidylinositol 3-kinase/AKT), activate cell cycle, and increase production of TNF- $\alpha$, transforming growth factor- $\beta$, and IL- $6 .{ }^{32}$ In addition, $\mathrm{CFB}$ activation fragment $\mathrm{Bb}$ is a serine proteinase and it is therefore possible that CFB may exert additional functions in cSCC growth beyond complement system activation. In summary, these results provide evidence for the roles of $\mathrm{C} 3$ and CFB in CSCC growth in vivo.

Recently, the indirect effects of complement system on tumor growth by altering the host immunoresponse have been emphasized. ${ }^{6,33,34}$ UV radiation and immunosuppression are important risk factors for initiation and development of cSCC. UV radiation has been shown to exert an immunosuppressive effect in skin, and CFB has recently been identified as an important mediator of UVA- and UVB-induced immunosuppression. ${ }^{35}$ CFB may serve as a molecular link between UV-induced immunosuppression in skin and development cSCC. Chronic inflammation is also a risk factor for cSCC, and complement activation has been shown to promote colitis-associated carcinogenesis through activation of IL-1 $\beta .{ }^{36}$ Complement activation releases anaphylatoxins $\mathrm{C} 3 \mathrm{a}$ and $\mathrm{C} 5 \mathrm{a}$, both of which may modulate tumor microenvironment by serving as chemotaxins and promoting generation of radical oxygen species, by increasing vascular permeability, and by increasing histamine release from mast cells. ${ }^{37}$

In summary, the results of this study show that complement system components $\mathrm{C} 3$ and $\mathrm{CFB}$ are overexpressed by tumor cells in cSCC in vivo, suggesting that these components play important roles in cSCC growth. In addition, our results show that $\mathrm{C} 3$ and $\mathrm{CFB}$ regulate proliferation and migration of cSCC cells and promote growth of $\mathrm{CSCC}$ xenografts in vivo. These results identify $\mathrm{C} 3$ and $\mathrm{CFB}$ as tumor cell-associated molecular markers for development of cSCC and suggest them as potential therapeutic targets in recurrent and metastatic cSCCs.

\section{Acknowledgments}

We thank Johanna Markola, Sari Pitkänen, and Sinikka Kollanus for technical assistance.

\section{Supplemental Data}

Supplemental material for this article can be found at http://dx.doi.org/10.1016/j.ajpath.2017.01.006.

\section{References}

1. Tufaro AP, Chuang JC, Prasad N, Chuang A, Chuang TC, Fisher AC: Molecular markers in cutaneous squamous cell carcinoma. Int J Surg Oncol 2011, 2011:231475

2. Rogers HW, Weinstock MA, Harris AR, Hinckley MR, Feldman SR, Fleischer AB, Coldiron BM: Incidence estimate of nonmelanoma skin cancer in the United States. Arch Dermatol 2010, 146:283-287

3. Kivisaari A, Kähäri VM: Squamous cell carcinoma of the skin: emerging need for novel biomarkers. World J Clin Oncol 2013, 4:85-90

4. Ratushny V, Gober MD, Hick R, Ridky TW, Seykora JT: From keratinocyte to cancer: the pathogenesis and modeling of cutaneous squamous cell carcinoma. J Clin Invest 2012, 122:464-472

5. Ricklin D, Hajishengallis G, Yang K, Lambris JD: Complement: a key system for immune surveillance and homeostasis. Nat Immunol 2010, 11:785-797

6. Rutkowski MJ, Sughrue ME, Kane AJ, Ahn BJ, Fang S, Parsa AT: The complement cascade as a mediator of tissue growth and regeneration. Inflamm Res 2010, 59:897-905

7. Janssen BJ, Gros P: Conformational complexity of complement component C3. Adv Exp Med Biol 2006, 586:291-312 
8. Rutkowski MJ, Sughrue ME, Kane AJ, Mills SA, Parsa AT: Cancer and the complement cascade. Mol Cancer Res 2010, 8:1453-1465

9. Terui T, Ishii K, Ozawa M, Tabata N, Kato T, Tagami H: C3 production of cultured human epidermal keratinocytes is enhanced by IFN $\gamma$ and TNF $\alpha$ through different pathways. J Invest Dermatol 1997, 108:62-67

10. Pasch MC, Van Den Bosch NH, Daha MR, Bos JD, Asghar SS: Synthesis of complement components C3 and factor B in human keratinocytes is differentially regulated by cytokines. J Invest Dermatol 2000, 114:78-82

11. Dovezenski N, Billetta R, Gigli I: Expression and localization of proteins of the complement system in human skin. J Clin Invest 1992, 90:2000-2012

12. Timar KK, Dallos A, Kiss M, Husz S, Bos JD, Asghar SS: Expression of terminal complement components by human keratinocytes. Mol Immunol 2007, 44:2578-2586

13. Riihilä PM, Nissinen LM, Ala-aho R, Kallajoki M, Grénman R, Meri S, Peltonen S, Peltonen J, Kähäri VM: Complement factor H: a biomarker for progression of cutaneous squamous cell carcinoma. J Invest Dermatol 2014, 134:498-506

14. Riihilä P, Nissinen L, Farshchian M, Kivisaari A, Ala-aho R, Kallajoki M, Grénman R, Meri S, Peltonen S, Peltonen J, Kähäri VM: Complement factor I promotes progression of cutaneous squamous cell carcinoma. J Invest Dermatol 2015, 135:579-588

15. Farshchian M, Kivisaari A, Ala-aho R, Riihilä P, Kallajoki M, Grénman R, Peltonen J, Pihlajaniemi T, Heljasvaara R, Kähäri VM: Serpin peptidase inhibitor clade A member 1 (SerpinA1) is a novel biomarker for progression of cutaneous squamous cell carcinoma. Am J Pathol 2011, 179:1110-1119

16. Farshchian M, Nissinen L, Grénman R, Kähäri VM: Dasatinib promotes apoptosis of cutaneous squamous carcinoma cells by regulating activation of ERK1/2. Exp Dermatol 2017, 26:89-92

17. Boukamp P, Petrussevska RT, Breitkreutz D, Hornung J, Markham A, Fusenig NE: Normal keratinization in a spontaneously immortalized aneuploid human keratinocyte cell line. J Cell Biol 1988, 106:761-771

18. Boukamp P, Stanbridge EJ, Foo DY, Cerutti PA, Fusenig NE: c-Ha-ras oncogene expression in immortalized human keratinocytes (HaCaT) alters growth potential in vivo but lacks correlation with malignancy. Cancer Res 1990, 50:2840-2847

19. Mueller MM, Peter W, Mappes M, Huelsen A, Steinbauer H, Boukamp P, Vaccariello M, Garlick J, Fusenig NE: Tumor progression of skin carcinoma cells in vivo promoted by clonal selection, mutagenesis, and autocrine growth regulation by granulocyte colonystimulating factor and granulocyte-macrophage colony-stimulating factor. Am J Pathol 2001, 159:1567-1579

20. Stokes A, Joutsa J, Ala-aho R, Pitchers M, Pennington CJ, Martin C, Premachandra DJ, Okada Y, Peltonen J, Grénman R, James HA, Edwards DR, Kähäri VM: Expression profiles and clinical correlations of degradome components in the tumor microenvironment of head and neck squamous cell carcinoma. Clin Cancer Res 2010, 16:2022-2035

21. Kivisaari AK, Kallajoki M, Mirtti T, McGrath JA, Bauer JW, Weber F, Königová R, Sawamura D, Sato-Matsumura KC, Shimizu H, Csikós M, Sinemus K, Beckert W, Kähäri VM: Transformation-specific matrix metalloproteinases (MMP)-7 and MMP-13 are expressed by tumour cells in epidermolysis bullosa-associated squamous cell carcinomas. Br J Dermatol 2008, 158:778-785

22. Kivisaari AK, Kallajoki M, Ala-aho R, McGrath JA, Bauer JW, Königová R, Medvecz M, Beckert W, Grénman R, Kähäri VM: Matrix metalloproteinase-7 activates heparin-binding epidermal growth factor-like growth factor in cutaneous squamous cell carcinoma. $\mathrm{Br} \mathrm{J}$ Dermatol 2010, 163:726-735

23. Kononen J, Bubendorf L, Kallioniemi A, Bärlund M, Schraml P, Leighton S, Torhorst J, Mihatsch MJ, Sauter G, Kallioniemi OP: Tissue microarrays for high-throughput molecular profiling of tumor specimens. Nat Med 1998, 4:844-847

24. Schneider CA, Rasband WS, Eliceiri KW: NIH Image to ImageJ: 25 years of image analysis. Nat Methods 2012, 9:671-675

25. Leivonen S-K, Ala-aho R, Koli K, Grénman R, Peltonen J, Kähäri VM: Activation of Smad signaling enhances collagenase-3 (MMP-13) expression and invasion of head and neck squamous carcinoma cells. Oncogene 2006, 25:2588-2600

26. Euhus DM, Hudd C, LaRegina MC, Johnson FE: Tumor measurement in the nude mouse. J Surg Oncol 1986, 31:229-234

27. Brideau G, Mäkinen MJ, Elamaa H, Tu H, Nilsson G, Alitalo K, Pihlajaniemi T, Heljasvaara R: Endostatin overexpression inhibits lymphangiogenesis and lymph node metastasis in mice. Cancer Res 2007, 67:11528-11535

28. Legoedec J, Gasque P, Jeanne JF, Fontaine M: Expression of the complement alternative pathway by human myoblasts in vitro: biosynthesis of $\mathrm{C} 3$, factor $\mathrm{B}$, factor $\mathrm{H}$ and factor I. Eur J Immunol 1995, 25:3460-3466

29. Gasque P, Julen N, Ischenko AM, Picot C, Mauger C, Chauzy C, Ripoche J, Fontaine M: Expression of complement components of the alternative pathway by glioma cell lines. J Immunol 1992, 149: $1381-1387$

30. Lee MJ, Na K, Jeong SK, Lim JS, Kim SA, Lee MJ, Song SY, Kim H, Hancock WS, Paik YK: Identification of human complement factor B as a novel biomarker candidate for pancreatic ductal adenocarcinoma. J Proteome Res 2014, 13:4878-4888

31. Lin K, He S, He L, Chen J, Cheng X, Zhang G, Zhu B: Complement component 3 is a prognostic factor of non-small cell lung cancer. Mol Med Rep 2014, 10:811-817

32. Cho MS, Vasquez HG, Rupaimoole R, Pradeep S, Wu S, Zand B, Han HD, Rodriguez-Aguayo C, Bottsford-Miller J, Huang J, Miyake T, Choi HJ, Dalton HJ, Ivan C, Baggerly K, LopezBerestein G, Sood AK, Afshar-Kharghan V: Autocrine effects of tumor-derived complement. Cell Rep 2014, 6:1085-1095

33. Corrales L, Ajona D, Rafail S, Lasarte JJ, Riezu-Boj JI, Lambris JD, Rouzaut A, Pajares MJ, Montuenga LM, Pio R: Anaphylatoxin C5a creates a favorable microenvironment for lung cancer progression. J Immunol 2012, 189:4674-4683

34. Gunn L, Ding C, Liu M, Ma Y, Qi C, Cai Y, Hu X, Aggarwal D, Zhang HG, Yan J: Opposing roles for complement component C5a in tumor progression and the tumor microenvironment. J Immunol 2012, 189:2985-2994

35. Byrne SN, Hammond KJ, Chan CY, Rogers LJ, Beaugie C, Marsh-Wakefield F, Thurman JM, Halliday GM: The alternative complement component factor B regulates UV-induced oedema, systemic suppression of contact and delayed hypersensitivity, and mast cell infiltration into the skin. Photochem Photobiol Sci 2015, 14: $801-806$

36. Ning C, Li Y-Y, Wang Y, Han G-C, Wang R-X, Xiao H, Li X-Y, Hou C-M, Ma Y-F, Sheng D-S, Shen B-F, Feng J-N, Guo R-F, Li Y, Chen G-J: Complement activation promotes colitis-associated carcinogenesis through activating intestinal IL-1 $\beta / \mathrm{IL}-17 \mathrm{~A}$ axis. Mucosal Immunol 2015, 8:1275-1284

37. Mamidi S, Höne S, Kirschfink M: The complement system in cancer: ambivalence between tumour destruction and promotion. Immunobiology 2015, 15:30092-30099 